\title{
RESENHAS
}

\section{A FELICIDADE E A TEORIA DA AMBIVALÊNCIA}

\author{
BAUMAN, Zygmunt. \\ A Arte da Vida. \\ Rio de Janeiro: Jorge Zahar Editor, 2009.
}

\section{POR}

\section{Bruno Azevedo Moura ${ }^{1}$}

\begin{abstract}
0 que há de errado em apresentar um questionamento sobre um conceito cuja própria existência seja inconcebível? Bauman ensina que embora nada esteja de errado com tal feito, a verdade é que o fato de haver algo de errado na dinâmica do conceito, tal como a questão da felicidade, pressupõe que este conceito seja marcado por uma realidade que a ele não seja compatível. Nesse sentido, um fator que nunca teria sido considerado para explicar um determinado fenômeno torna-se, repentinamente, sua causa. A Arte da Vida introduz este nível de discussão, isto é, uma discussão que não está preocupada em reproduzir um modelo ou modelos de vida que ensinam como viver. Ao contrário, o livro atém-se à concepção de que a construção do modelo da vida não depende de responsabilidades, méritos, ou realizações individuais. Depende de múltiplas condições sociais que nos são previamente escolhidas e determinadas, como, por exemplo, a insegurança que sentimos com a identidade que construímos, o vínculo
\end{abstract}

\footnotetext{
${ }^{1}$ Mestrando do Programa de Pós-Graduação em Sociologia do Departamento de Sociologia da Universidade de Brasília (UnB). Pesquisador do Núcleo de Pesquisa sobre o Ensino Superior da Universidade de Brasília (NESUB). End. Eletrônico: bruno_moura@hotmail.com
} 
íntimo que sentimos entre a felicidade e o volume e a qualidade do consumo, a necessidade que sentimos de ter nossa posição social reconhecida, a necessidade que sentimos de estar à frente de outras pessoas, a obrigação que sentimos de não estarmos parados ou, ainda, de dar a entender que estamos ociosos e assim por diante. Em outras palavras, Bauman centraliza a discussão geral do livro em torno da demonstração que estilos e modelos de vida são construtos sociais, decisões previamente decididas. Contudo, é bom adiantar que "a arte da vida" permite que escolhas moralizantes e compassivas ao bem do Outro sejam perpetradas pelos indivíduos. Ao revelar a responsabilidade que temos com o Outro, A Arte da Vida expõe a visão humanista e otimista do autor, que acredita na universalização e aplicação geral de atitudes e ações éticas no contexto da coletividade.

A pergunta corriqueira "o que está de errado com isso ou aquilo", quando se refere a alguns princípios básicos da vida social, mostra o cerne da sociedade líquido-moderna: a prevalência do inconcebível e do não imaginado. No contexto da sociedade líquido-moderna, há de se ressaltar o inconcebível, o inacreditável, o impensado, o inviável, no sentido que tudo culmina em um pseudo-equilíbrio entre contrastes, entre visíveis opostos. 0 que para nós, tanto leigos quanto intelectuais, seria uma situação taxada como inconcebível, impossível de ser sustentada, para a lógica da sociedade líquido-moderna, os opostos se atraem, as contradições se atracam reciprocamente, o abstruso faz sentido, o inimaginável traz compreensão. 0 que irrefletidamente seria descartado se transforma no âmago da questão, como forma de se explicar um fenômeno. Guinado pela certeza de que o mundo contemporâneo não é explicado convencionalmente por padrões lógicos que se vinculam a fenômenos sociais, a temática de A Arte da Vida perpassa os campos da filosofia, da dialética, do pós-estruturalismo e da sociologia, em busca de respostas que dão conta de explicar as máximas vivenciadas.

Nesta obra, Zygmunt Bauman argumenta que a nossa sociedade líquidomoderna tem dissertado acerca não apenas do que vem a ser felicidade, como também acerca da possibilidade de haver defeitos e equívocos no âmago do conceito de felicidade.

A felicidade humana é pautada e transformada no objeto da teoria da ambivalência. Os pressupostos teóricos do pensamento do sociólogo polonês transmitem a concepção de que o projeto humano voltado à vida esteja condicionado pela ambivalência, isto é, pela certeza do que é e pela incerteza do que é, ou, ainda, pela certeza do que não é e pela incerteza do que não é. 
Nesse contexto, os fenômenos têm sido explicados por opostos radicalmente diferentes que têm se complementado, e que têm sido usados tanto para descrever quanto para interpretar e analisar fenômenos sociais. Muitas vezes as causas têm sido enganadas pelos efeitos e vice-versa. Além disso, por causa do processo de complexificação na maneira das variáveis se relacionarem no âmbito da esfera científica, entende-se que as variáveis além de terem multiplicado drasticamente, também têm demonstrado determinações inversas de dependência. Apesar da consolidação da teoria do caos, Bauman recorre à explicação sociológica e filosófica pautada na coerência de uma perspectiva ambivalente nos processos teóricos e metodológicos de construção de conhecimento. Aliás, essa percepção teórica é recorrente na maioria de suas obras, tais como A Sociedade Individualizada (2008), Medo Líquido (2008), Vida para Consumo (2008), Tempos Líquidos (2007), Modernidade e Ambivalência (1999).

No interior da sociedade contemporânea, que é caracterizada pelo individualismo, pelo consumismo e pela liquidez, o impacto total das descobertas, das melhorias das máquinas, das inovações técnico-científicas, que são de fácil acesso, que são simples de serem aprendidas e utilizadas, e que pressupõe um engajamento momentâneo, tem contribuído para ganhar e economizar tempo. No entanto, esse avanço tecnológico também tem causado um impacto bastante ambíguo sobre a soma total de felicidade. A despeito de tanto desenvolvimento econômico, a despeito do esforço coletivo para aumentar o produto nacional bruto (PNB), a despeito de tanta riqueza e casos de enriquecimento individual, enfim, Bauman infere que apesar de haver uma correlação íntima entre felicidade e crescimento econômico, este último não tem contribuído para geração do volume e profundidade de felicidade. Daí a razão do título na introdução $O$ que há de errado com a felicidade? - contrário ao que era de se esperar, a felicidade de forma alguma está, pura e objetivamente, atrelada à riqueza.

Quanto a isso, Bauman relata as conclusões de Richard Layard (2005) de que os índices de felicidade só crescem de modo significativo até o ponto de superação da pobreza e da carência, isto é, são máxime significativos quando realizam as necessidades essenciais, as necessidades de sobrevivência do ser humano. Após este ponto, com novos incrementos de riqueza, os índices de felicidade param de subir.

0 primeiro capítulo da obra discute alguns assuntos relacionados a "o que é a felicidade?", "como pode ser alcançada?" "varia de acordo com a geração 
ou a época social?" "pode alcançá-la de uma vez por todas?". Essas perguntas revelam as preocupações de Bauman, que, a partir da filosofia, submete o conceito da felicidade a questionamentos e problematizações.

No segundo capítulo, Bauman retrata os indivíduos como artistas da vida, queira tenham conhecimento disso ou não, ou queria aceitam ou não. Ser artista da vida implica que a vida é uma obra de arte que, no contexto dos tempos líquidomodernos, segue um plano inspirado na rapidez, no assunto do momento, bem como naquilo que o autor denomina de "encontro com o Destino", ou seja, a sorte de um dia ser descoberto ou promovido por alguém. É preciso, então, aproveitar todas as chances. Nas palavras do autor: "Estamos certos em ter esperança e até a expectativa de que a boa sorte venha em nossa direção, e devemos ajudá-la nesse sentido - estendendo ao máximo nossa imaginação individual e empregando com habilidade todos os recursos que possam reunir" (p. 94). Este processo de praticar a arte da vida significa, sobretudo, condutas de autodeterminação e auto-afirmação. Este estilo de vida consolida a idéia de que viver pressupõe viver autenticamente, no sentido de "ser outra pessoa e não o que as pressões externas coagem todo mundo a ser" (p. 109).

0 terceiro e último capítulo ventila a noção de que a arte de viver é dirigida por decisões e disposições que são produzidas por escolhas individuais. Por isso duas perspectivas de atitude para com o viver no mundo são levantadas. Em primeiro lugar, em essência, ambas perspectivas demonstram que as escolhas acerca da objetividade e da subjetividade da vida são feitas pelos autores desta vida. Apesar dessa semelhança, em contrapartida, uma demonstra o compromisso do homem com si mesmo; a outra, o compromisso do homem com os outros. Dessa forma, Bauman pincela as diferenças na concepção filosófica de vida e mundo de Friedrich Nietzsche (2005) e Emmanuel Levinas (2007). Enquanto 0 homem de Nietzsche deve propender às características do "Homem Superior" ou "Super-Homem" - homem voltado aos seus valores e conceitos intrínsecos, às suas preocupações e às ambições do seu ego -, o homem em Levinas se atém à categoria da responsabilidade, sendo esta uma preocupação com o Outro. Nesse sentido, "a responsabilidade pelo Outro é que é a estrutura essencial, primária e fundamental de minha subjetividade [...] Sou porque sou para os outros. Para todos os fins e propósitos práticos, 'ser' e 'ser para os outros' são sinônimos" (p. 159).

Dessa forma, a felicidade também depende dessas perspectivas de entender 
tanto o homem quanto o mundo. À mesma medida que o entendimento acerca do comportamento do homem no mundo é reconhecido pela pluralidade de percepções e opiniões, assim também o conceito de felicidade está inserido na história do homem. Trata-se de uma concepção duvidosa, ambígua, isto é, de uma concepção que se esquiva de um rótulo universal, de uma classificação que seja transversal quanto à definição da maneira que se almeja viver. Por isso, a arte da vida é estar constantemente fazendo o que os homens em sociedade geralmente fazem: sondar a felicidade. Sondar a felicidade ou "tateá-la em busca de luz" (p. 161) é explorar e conhecer suas possibilidades, seu horizonte socialmente construído e suas definições e qualificações, as quais são ancoradas em um espaço e tempo de um determinado processo sócio-histórico. Em suma, trata-se de uma leitura que relativiza a felicidade e que a redimensiona, tendo por base uma perspectiva clássica baumaniana, cuja teorização é pautada no contexto de categorias de pensamento que realçam a ambivalência.

\section{REFERÊNCIAS}

NIETZSCHE, Friedrich. Ecce homo. São Paulo: Martin Claret, 2005.

LEVINAS, Emmanuel. Ética e infinito. São Paulo: Edições 70, 2007.

LEYARD, Richard. Happiness: Lessons from a new science. London: Penguin, 2005. 